\title{
АКАДЕМІЧНА ПРОКРАСТИНАЦІЯ В ІНОЗЕМНИХ СТУДЕНТІВ БАКАЛАВРАТУ В УМОВАХ ЛІНГВОКУЛЬТУРНОЇ ІНТЕГРАЦЇ̈
}

\author{
Олена Журавльова \\ aln_frolova@gmail.com \\ Східноєвропейський національний університет імені Лесі Українки, Україна \\ Лариса Засскіна \\ lora.zasyekina@gmail.com \\ Університет Англія Раскін, Велика Британія \\ Олександр Журавльов \\ zhuravlov.oleksandr@eenu.edu.ua \\ Східноєвропейський національний університет імені Лесі Українки, Україна
}

Received May 13, 2019; Revised May 28, 2019; Accepted June 19, 2019

Анотація. У статті обгрунтовано актуальність вивчення чинників акультурації та мовної адаптації у контексті дослідження специфіки прояву прокрастинації іноземними студентами. Висвітлено особливості операціоналізації вказаних понять у сучасній науковій літературі. Вибірку дослідження склали іноземні студенти $(\mathrm{n}=41)$, які навчаються за освітнім рівнем «бакалавр» у двох вищих навчальних закладах України. Результати кореляційного аналізу свідчать про позитивний взаємозв'язок прокрастинації із загальним рівнем прояву стресу акультурації $(\mathrm{r}=0.43, \mathrm{p}<0,01)$, а також такими його аспектами як акультураційний страх $(\mathrm{r}=0.46, \mathrm{p}<0,01)$, сприйнята дискримінація $(\mathrm{r}=0.37, \mathrm{p}<0,05)$, почуття провини $(\mathrm{r}=0.31$, $\mathrm{p}<0,05)$. Вагоме значення аспектів мовної інтеграції у контексті вивчення тематики прокрастинації підтверджено зафіксованими прямими значущими кореляційними зв'язками із загальною шкалою мовної тривожності $(\mathrm{r}=0.59, \mathrm{p}<0,001)$, страхом негативної оцінки $(\mathrm{r}=$ $0.62, \mathrm{p}<0,001)$, страхом спілкування $(\mathrm{r}=0.62, \mathrm{p}<0,001)$ та складання іспитів $(\mathrm{r}=0.47, \mathrm{p}<0,01)$.

Ключові слова: прокрастинація, акультураційний стрес, мовна адаптація, мовна тривожність, іноземні студенти.

Academic Procrastination Among International Undergraduate Students Under the Conditions of Linguistic and Cultural Integration.

Abstract. The article is focused on revealing the factors of acculturation and language adaptation through the study of the specific character of procrastination in international students. The specific features of the operationalization of these concepts in modern psychological literature. The peculiarities of the operationalization of these concepts in modern scientific literature are highlighted. Among the research participants were international undergraduate students $(n=41)$ who study at two higher education institutions of Ukraine. Results of the correlation analysis indicate a positive correlation between procrastination with the general level of acculturation stress $(r=0.43, p<0.01)$, as well as its aspects as an acculturation fear $(\mathrm{r}=0.46, \mathrm{p}<0.01)$, discriminated perception $(\mathrm{r}=0.37, \mathrm{p}$ $<0.05)$, feeling of guilt $(\mathrm{r}=0.31, \mathrm{p}<0.05)$. Great significance of the aspects of language integration in the context of studying the subject of procrastination is confirmed by stable direct correlations with the general scale of speech anxiety $(r=0.59, \mathrm{p}<0.001)$, fear of negative evaluation $(\mathrm{r}=0.62, \mathrm{p}<0.001)$, fear of communication $(r=0.62, p<0.001)$, and exams $(r=0.47, p<0.01)$.

(ㄷ) Журавльова Олена, Засєкіна Лариса, Журавльов Олександр, 2019. This is an Open Access article distributed under the terms and conditions of the Creative Commons Attribution 4.0 International Licence (http://creativecommons.org/ licenses/by/4.0).

East European Journal of Psycholinguistics, 6(1), 82-93. https://doi.org/10.5281/zenodo.3383927 
Keywords: procrastination, acculturation stress, language adaptation, language anxiety, foreign students

\section{1. Ветуп}

Трансформація соціальної реальності, зміна іiі ціннісного простору i модернізація усіх сфер суспільного життя супроводжується значним розширенням спектру зобов'язань людини та встановленням жорстких термінів для їх виконання. Бажання особистості відповідати суспільним стандартам успішності породжує необхідність ефективного управління власним часом, свідомої регуляції своєї діяльності. Водночас, закономірно, що надмірна інтенсивність інформаційних потоків і нестабільність соціального середовища досить часто відіграють роль стресогенного чинника та детермінують дезадаптацію індивіда, що виявляється у недотриманні ним самостійно встановлених термінів, а, відтак, призводить до зниження продуктивності його життя. Окреслене явище знайшло відображення у понятті «прокрастинація» та зайняло важливе місце у колі інтересів сучасних дослідників.

Термін «прокрастинація» походить від латинського procrastinatio (лат. pro - «вперед, далі», crastinate - «завтра»), що дослівно тлумачиться як «відкладання на завтра». Складність та багатомірність прояву цього феномену у різних видах діяльності породжує різноманіття визначень та методологічних позицій до його інтерпретації. Однак, аналіз низки наукових праць (Wendelien van Eerde, Klingsieck, 2018; Chowdhury, Pychyl 2018; Markiewicz, 2018; Steel, 2007; Ferrari, 1995) дає змогу виокремити спільні особливості у множині представлених поглядів та узагальнити їх у визначенні прокрастинації як свідомого добровільного відкладання попередньо запланованих важливих справ, що призводить до очікуваних негативних наслідків і супроводжується відчуттям емоційного дискомфорту. Таким чином, суттєвим індикатором цього конструкту є саме ірраціональний характер відтермінування діяльності (Balkis \& Duru, 2019; Tibbett \& Ferrari, 2015; Haghbin 2015; Klingsieck 2013; Steel, 2007). Відтак, прокрастинація є неадаптивною стратегією поведінки (Lindblom-Ylänne, 2015), яку у традиційному розумінні пов'язують із такими явищами як пасивність, дисфункціональність, відсутність самоорганізації тощо (Колтунович, Поліщук, 2017). 3 огляду на це, особливу увагу науковці акцентують на деструктивних наслідках іiі прояву, серед яких найчастіше відзначаються психічні проблеми (депресія, тривога, страх) (Tibbett \& Ferrari, 2015), соматичні порушення (погіршення загального самопочуття, гіпофункція імунної системи, головний біль тощо) (Sirois, Pychyl, 2017; Klingsieck 2013), труднощі в інтерперсональних стосунках (Goldin, Katz, Kuziemko, 2006; Steel, Ferrari, 2013), фінансові втрати (Sirois, Pychyl, 2013; Gamst-Klaussen, Steel \& Svartdal 2019).

Попри це, прокрастинація стрімко набуває масштабів соціальної хвороби. Так, близько 15 - 25 \% дорослого населення схильні до стійкого виявлення дилаторної поведінкової тенденції. Значно вищі показники прояву вказаної особливості демонструють студенти: систематичне зволікання серед них 
властиве 80-90\% осіб. Водночас близько $50 \%$ з них констатують, що в результаті такого відтермінування зазнали значимих негативних наслідків (Markiewicz, Dziewulska, 2018).

Слід зауважити, що студентський вік є періодом активної соціалізації індивіда, розвитку вищих психічних функцій, становлення інтелектуальної системи та особистості загалом. Поряд із цим, початок навчання у ВН3 є стресогенним життєвим періодом, оскільки передбачає інтенсивні повсякденні навчальні навантаження (Грабчак, 2016). Відтак, закономірним є той факт, що саме вказана категорія осіб найчастіше стає об'єктом наукових досліджень, зорієнтованих на вивчення тематики прокрастинації. Попри це, деякі ії аспекти залишаються недостатньо висвітленими. Однією із таких прогалин у сучасних умовах інтенсивних інтеграційних процесів є дослідження специфічних особливостей прояву прокрастинації іноземними студентами.

За даними Міністерства освіти і науки України станом на 2018 рік у нашій країні навчалось понад 75 тис. студентів із 154 країн світу, 3-поміж яких найчисельніші групи становить молодь із Індії, Марокко, Азербайджану, Туркменістану, Нігерії, Єгипту, Туреччини. Жителі кожної країни мають власні традиції, звичаї, світогляд, що формують самобутність кожної соціальної групи. Відтак, іноземні студенти змушені адаптуватись як до нових академічних, так і культурних умов. Зважаючи на це, окрім змінних, які традиційно розглядаються науковцями у ролі детермінант прокрастинації (наприклад, аверсивність задачі, самооцінка, особливості мотивації, рівень нейротизму, конфлікт ролей тощо), особливої уваги, на нашу думку, заслуговують стрес акультурації та мовні труднощі.

Акультурація - це процес культурних та психологічних змін в результаті контакту представників різних соціокультурних груп (Berry, 2005).

Початковий етап включення індивіда у нове соціальне середовище супроводжується значним розширенням меж власного досвіду та може зумовлювати виникнення почуття самотності, нестачі тісних інтерперсональних відносин, туги за домом, культурний шок, страх расової, етнічної чи релігійної дискримінації (Kornienko, Shamrova, Kvesko, Kornienko, Nikitina, Chaplinskaya, 2016). Згідно $з$ Дж. Расселл та колег, вказані психологічні труднощі тісно корелюють із фізичними проблемами: розладами сну, втратою апетиту, зниженням загального енергетичного тонусу, підвищеною вразливістю до різних хвороб, стійкими соматичними скаргами (Russell, Rosenthal \& Thomson, 2010).

Доцільно зауважити, що соціокультурна адаптація кожного студента характеризується різною динамікою, успішність якої значною мірою залежить від його індивідуальних особливостей (розвиненості адаптивних механізмів, загального рівня психічної зрілості тощо). Відтак, виокремлюють різні типи акультурації (Ряднова, Безега, Безкоровайна, Воскресенська, ПераВасильченко, 2018):

1. Повне прийняття особистістю норм, звичаїв цінностей нового соціокультурного середовища, які поступово починають домінувати над іiі власними етнічними рисами; 
2. Часткова інтеграція індивіда у нові для нього умови, що виявляється у прийнятті виключно «обов'язкових норм» конкретної соціальної спільноти, при одночасному збереженні ключових характеристик своєї етнічної групи;

3. Відмова від прийняття норм та цінностей нового соціокультурного середовища та дистанціювання від його представників.

3 огляду на це, припускаємо, що неуспішна акультурація може послугувати причиною дезадаптації особистості, а, відтак, призвести до проявів прокрастинації.

Важливою умовою повноцінної інтеграції іммігранта у незвичну для нього соціальну реальність $є$ оволодіння іноземною лексикою у мірі, необхідній для повноцінної комунікації на побутовому рівні та реалізації усього спектру академічних задач. Так, С. Лі зауважив, що знання мови $\epsilon$ найкращим предиктором психологічної, соціокультурної адаптації та задоволення іноземцем потреби у соціальній підтримці (Lee, 2008).

А. Жанібек виокремлює два типи позиціонування індивіда у контексті засвоєння іноземної мови (Zhanibek, 2001):

1. Самовдосконалення, що виявляється у позитивній емоційній оцінці власного прогресу у розвитку мовних навичок;

2. Самоусунення, що передбачає негативне сприйняття своєї компетентності в окресленій сфері, а, відтак, детермінує виникнення мовної тривожності.

Широкий спектр наукових досліджень підтвердив наявність кореляційного зв'язку між рівнем прояву тривоги іноземцем та успішністю мовної інтеграції. Значний внесок у вивчення вказаної проблематики здійснив М. Горовіц, на думку якого, мовну тривожність слід розглядати як складний $і$ багатовимірний феномен самосприйняття, переконань, почуттів, поведінкових патернів, пов'язаних із освоєнням іноземної мови. Конструкт мовної тривожності включає три взаємопов'язані негативні виміри: 1) страх спілкування; 2) страх тестування (складання іспиту); 3) страх негативної оцінки (Horwitz, Horwitz \& Cope, 1986).

Мовна тривожність має такі само клінічні прояви, як й інші типи цієї властивості: пришвидшене серцебиття, посилене потовиділення, тремтіння, занепокоєння, нездатність сконцентруватись, забудькуватість. У дослідженні, проведеному М. Хашемі та М. Аббасі, респонденти описували й інші характерні для них ознаки мовної тривожності, серед яких: почервоніння, тремтіння голосу, занадто швидкий або ж, навпаки, повільний темп мовлення, потирання долонь, зниження результативності тощо (Hashemi, Abbasi, 2013). Негативні наслідки, що виникають у процесі засвоєння іноземної мови, - результат розподілу індивідом уваги між когніціями, зорієнтованими на виконання необхідних завдань та когніціями, пов'язаними із власною особистістю, що знижує його загальну продуктивність (Král'ová, Sorádová, 2015).

\section{2. Методи дослідження}

3 огляду на актуальність окресленої проблематики, мета нашої наукової розвідки полягає в установленні взаємозв'язку між особливостями 
акультурації, мовної інтеграції іноземних студентів та їхньою схильністю до прояву прокрастинації.

Для реалізації сформульованої мети було застосовано такі методи: теоретичні (аналіз, синтез, узагальнення, систематизація наукової літератури 3 досліджуваної проблеми); емпіричні (Procrastination Scale (Lay), An Acculturative stress scale (Sandhu, Asrabadi), The foreign language classroom anxiety scale (Horwitz)); методи описової статистики, кореляційний аналіз.

Вибірку дослідження склали іноземні студенти $(\mathrm{n}=41)$, які здобувають освіту у вищих навчальних закладах України: Східноєвропейському національному університеті імені Лесі Українки, Луцькому національному технічному університеті. Серед них - 29\% жінки, $71 \%$ - чоловіки. Усі респонденти були повідомлені про анонімний характер опитування та можливість резигнації на будь-якому етапі.

\section{3. Обговорення результатів}

Описову статистику діагностованих змінних представлено в таблиці 1.

Таблиця 1

Описова статистика діагностованих змінних

\begin{tabular}{|c|c|c|c|c|}
\hline Змінні & $\mathbf{M}$ & SD & Min & Max \\
\hline Вік & 25.14 & 5 & 19 & 40 \\
\hline Прокрастинація (PS) & 52.7 & 9.85 & 24 & 88 \\
\hline Сприйнята дискримінація (PD) & 22.19 & 7.6 & 1 & 5 \\
\hline Туга за домом $(\mathrm{H})$ & 12.36 & 3.82 & 1 & 5 \\
\hline Сприйнята ненависть (РН) & 12.66 & 5.2 & 1 & 5 \\
\hline Страх $(\mathrm{F})$ & 8.78 & 3.64 & 1 & 5 \\
\hline Стрес пов'язаний зі змінами / & & & 1 & 5 \\
\hline Культурний шок (SD) & 8.07 & 2.95 & & \\
\hline Почуття провини (G) & 4.78 & 2.41 & 1 & 5 \\
\hline Загальний рівень & & & & \\
\hline акультураційного стресу (Т) & 93 & 28.75 & 42 & 158 \\
\hline Страх спілкування (СА) & 29.07 & 7.87 & 1 & 5 \\
\hline Страх тестування (ТА) & 38.62 & 9.01 & 1 & 5 \\
\hline Страх негативної оцінки (FN) & 16.38 & 6.18 & 1 & 5 \\
\hline $\begin{array}{l}\text { Загальний рівень мовної } \\
\text { тривожності (LA) }\end{array}$ & 84.07 & 21.37 & 51 & 121 \\
\hline
\end{tabular}

Основна отримана демографічна інформація включила два показники: стать та вік студентів. Аналіз вказаних даних засвідчив відсутність лінійного зв'язку цих параметрів із рівнем прокрастинації ( $\mathrm{r}=0.00$ та $\mathrm{r}=0.26$ відповідно). Слід зауважити, що подібні емпіричні висновки були представлені й іншими науковцями, наприклад, Дж. Феррарі, Дж. Каллаганом, І. Ньюбігіном, Г. Шауенбургом (Ferrari, Callaghan, Newbegin 2005; Schouwenburg, 2004). 
Подальша робота 3 даними полягала у перевірці припущення згідно 3 яким систематичний прояв дилаторної поведінкової тенденції характерний саме для тих іноземних студентів, які відчувають труднощі із адаптацією до нового соціокультурного середовища. Для цього використано коефіцієнт Пірсона, результати застосування якого відображено у таблиці 2.

Таблиця 2

Взаємозв'язок прокрастинації зі стресом акультураиії

\begin{tabular}{cccccccc}
\hline & PD & H & PH & F & SD & G & T \\
\hline PS & $0.37^{*}$ & 0.18 & 0.29 & $0.46^{* *}$ & 0.28 & $0.31^{*}$ & $0.43^{* *}$ \\
\hline
\end{tabular}

Примітка: *p $<0,05 ; * * p<0,01$.

Тісний позитивний кореляційний зв'язок $(\mathrm{r}=0.43, \mathrm{p}<0,01)$ виявлений між прокрастинацією та акультураційним стресом слугує підтвердженням сформульованої нами гіпотези. Відзначимо, що зв'язок схильності до відкладання респондентами важливих справ прослідковується не лише із загальним рівнем успішності культурної інтеграції, але й з ії окремими аспектами. Зокрема, найбільш вираженою є взаємозалежність між прокрастинацією та акультураційним страхом ( $\mathrm{r}=0.46, \mathrm{p}<0,01)$, який супроводжується ідентифікацією нового оточення як ворожого. Оцінку подібного соціального відчуження передбачає і шкала «сприйнятої дискримінації», відтак, встановлення прямої кореляції $(\mathrm{r}=0.37, \mathrm{p}<0,05)$ іiї показників зі схильністю до зволікання вважаємо закономірним. Очевидно, умови сегрегації та побоювання ймовірної загрози насильства посилюють фундаментальну потребу особистості у безпеці. Як зазначають Д. Сандху та С. Асрабаді (Sandhu, Asrabadi 1994), природньою реакцією іноземця $\epsilon$ пошук підтримки у нечисельної на території чужої країни групи співгромадян та одночасна відсутність спроб налагодити комунікацію із членами нової соціальної спільноти. 3 огляду на це, грунтуючись на ідеях Л. Рорера (Rorer, 1983) припускаємо, що однією з детермінант прокрастинації досліджуваних є страх власного успіху. У цьому разі особистість переконана, що демонстрація більш ефективної діяльності у порівнянні з іншими членами власної референтної групи створює загрозу бути відторгнутою. А, відтак, 3 метою збереження відчуття безпеки та приналежності студент відкладає певні задачі. 3 іншого ж боку, спираючись на теоретичні погляди Ф. Дюбов та колег (DuBow, McCabe, Kaplan, 1979), слід зауважити, що іноземці часто уникають саме тих завдань, які передбачають взаємодію з особами, схильними до проявів дискримінації. Окрім цього було зафіксовано значущий кореляційний зв'язок прокрастинації із почуттям провини $(\mathrm{r}=0.31, \mathrm{p}<0,05)$. Адаптація до нової культури інколи сприймається емігрантами як зрада власної, а отже отримані показники можуть свідчити про схильність відтерміновувати задачі, ефективна реалізація яких залежить від успішної ресоціалізації. Водночас, 
незначущою виявилась кореляція прокрастинації з тугою за домом (r = 0.18), стресом пов' язаним зі змінами $(\mathrm{r}=0.28)$, сприйнятою ненавистю $(\mathrm{r}=0.29)$.

Подальший аналіз отриманих емпіричних даних вказує на вагоме значення аспектів мовної інтеграції іноземних студентів у контексті вивчення проблематики прокрастинації (табл.3).

Таблиця 3

Взаємозв'язок прокрастинації̈ з мовною тривожністю

\begin{tabular}{ccccc}
\hline & CA & TA & FN & LA \\
\hline PS & $0.59 * * *$ & $0.47 * *$ & $0.62 * * *$ & $0.59 * * *$ \\
\hline
\end{tabular}

Примітка: $* * \mathrm{p}<0,01 ; * * * \mathrm{p}<0,001$

Окрім тісного позитивного взаємозв `язку $(\mathrm{r}=0.59, \mathrm{p}<0,001)$ схильності до зволікання із загальним рівнем прояву мовної тривожності, значуща взаємозалежність була виявлена і 3 усіма іншими діагностичними параметрами, що відображають труднощі у засвоєнні нової мови. Найвираженішою ( $\mathrm{r}=0.62, \mathrm{p}<0,001)$ є кореляція зі страхом негативної оцінки. Джерелом тривоги у цьому випадку $\epsilon$ побоювання справити негативне враження на соціальне оточення, недосконало розмовляючи іноземною мовою. Отож, студенти прокрастинують у межах тих завдань (ситуацій), які передбачають оцінку їхніх мовних умінь. Закономірним, 3 огляду на це, вважаємо зв'язок дилаторної поведінки зі страхом спілкування (r =0.62, $\mathrm{p}<0,001)$, ймовірно, що у випадку тривоги 3 приводу нестачі навичок для повноцінної комунікації з носіями іноземної мови, студент уникатиме задач пов’язаних $з$ подібною інтеракцією. Тісна кореляція зволікання зі страхом тестування (складання іспиту) ( $\mathrm{r}=0.47, \mathrm{p}<0,01)$, на нашу думку, може свідчити про використання прокрастинації студентом у ролі механізму психологічного захисту, адже, наприклад, відтерміновуючи підготовку до іспиту, він отримує перевагу, яка полягає у можливості пояснити невдачу обмеженим часовим ресурсом, а не власною некомпетентністю.

Цікавими в контексті нашого дослідження виявились результати аналізу специфіки взаємозв'язків між особливостями акультурації та мовної адаптації. Серед показників кореляції між шкалами двох методик не виявлено жодного незначущого (табл.4).

Таблиця 4

Взаємозв'язок стресу акультурації з мовною тривожністю

\begin{tabular}{cccccccc}
\hline & $\mathrm{PD}$ & $\mathrm{H}$ & $\mathrm{PH}$ & $\mathrm{F}$ & $\mathrm{SD}$ & $\mathrm{G}$ & $\mathrm{T}$ \\
\hline $\mathrm{CA}$ & $0.58^{* * *}$ & $0.4 * *$ & $0.46^{* *}$ & $0.62^{* * *}$ & $0.53^{* * *}$ & $0.39^{*}$ & $0.65^{* * *}$ \\
$\mathrm{TA}$ & $0.53 * * *$ & $0.38^{*}$ & $0.47^{* *}$ & $0.58^{* * *}$ & $0.47 * *$ & $0.37 *$ & $0.6^{* * *}$ \\
$\mathrm{FN}$ & $0.62 * * *$ & $0.41^{* *}$ & $0.49^{* *}$ & $0.66^{* * *}$ & $0.62 * * *$ & $0.46^{* *}$ & $0.7 * * *$ \\
& $0.62 * * *$ & $0.43^{* *}$ & $0.51 * * *$ & $0.66^{* * *}$ & $0.58^{* * *}$ & $0.44^{* *}$ & $0.7 * * *$ \\
\hline
\end{tabular}

Примітка: ${ }^{*} \mathrm{p}<0,05 * * \mathrm{p}<0,01 ; * * * \mathrm{p}<0,001$. 
Отже, отримані дані свідчать про потребу вивчення вказаних процесів у нероздільній єдності та дають змогу констатувати, що успішне включення особистості у нове соціокультурне середовище неможливе без достатнього рівня мовної інтеграції.

\section{4. Висновки}

Прокрастинація $\epsilon$ стабільною, неадаптивною формою поведінки, яка дезорганізує функціонування особистості (Ferrari, Crum, Pardo, 2018). Однією 3 найважливіших перешкод на шляху формування системи заходів зорієнтованих на мінімізацію ï негативних наслідків $\epsilon$ відсутність чіткого розуміння предикторів виникнення вказаної деструктивної тенденції. Відтак, дослідження прокрастинації у контексті акультурації та мовної адаптації особистості, з одного боку, суттєво поглиблює розуміння сутності вказаного феномену, $з$ іншого, створює основу для оптимізації шляхів включення іноземних студентів у нову соціальну реальність та сприяння ефективному функціонуванню у академічному середовищі, конструктивній побудові міжособистісних відносин у новій для них соціальній реальності.

Відтак, у цьому контексті на особливу увагу заслуговує той факт, що чинники стресу акультурації, які безпосередньо не взаємопов'язані 3 прокрастинацією, попри демонстрацію залежності 3 предикторами мовної тривожності, все ж опосередковано через них можуть здійснювати певний уплив на рівень сформованості поведінкової тенденції іноземних студентів до зволікання.

\section{Література \\ References}

Грабчак О. Особливості академічної прокрастинації студентів-першокурсників// Педагогіка і психологія професійної освіти. 2016., № 4. С. 210-218

Колтунович, Т.А., Поліщук, О.М. Прокрастинація - конфлікт між «важливим» i «приємним»// Young Scientist. 2017. Вип. 5(45). С. 211-218.

Ряднова, В.В., Безега, Н.М., Безкоровайна, І.М., Воскресенська, Л.К., Пера-Васильченко, А.В. (2018). Психологічні особливості процесу адаптації й організації навчання студентів-іноземців. Актуальні питання медичної (фармацевтичної) освіти іноземних громадян: проблеми та перспективи.Збірник наукових статей. С. 74-76.

Balkis, M., Duru, E. (2019). Procrastination and Rational/Irrational Beliefs: A Moderated Mediation Model. Journal of Rational-Emotive \& Cognitive-Behavior Therapy. doi:10.1007/s10942-019-00314-6

Berry, J. W. (2005). Acculturation: Living successfully in two cultures. International Journal of Intercultural Relations, 29(6), 697-712. http://dx.doi.org/10.1016/j.ijintrel.2005.07.013

Chowdhury, S.F., Pychyl, T.A. (2018). A critique of the construct validity of active procrastination. Personality and Individual Differences, 120, 7-12. DOI: https://doi.org/ 10.1016/j.paid.2017.08.016.

DuBow, F. McCabe, E., Kaplan, G. (1979). Reactions to Crime: A Critical Review of the Literature, Unpublished report. Center for Urban Affairs, Northwestern University, Evanston, IL. 
Ferrari J.R., Crum K.P., Pardo M.A. (2018), Decisional procrastination: Assessing characterological and contextual variables around indecision. Current Psychology, 37(2), doi: 10.1007/s12144-017-9681-x.

Ferrari, J. R., Johnson, J. L., McCown, W. G. (1995). The Plenum series in social/clinical psychology. Procrastination and task avoidance: Theory, research, and treatment. N.Y.: Plenum Press. doi: 10.1007/978-1-4899-0227-6

Ferrari, J. R., O'Callaghan, J., Newbegin, I. (2005). Prevalence of Procrastination in the United States, United Kingdom, and Australia: arousal and avoidance delays among adults. North American Journal of Psychology, 7(1), 1-6.

Gamst-Klaussen, T., Steel, P., Svartdal, F. (2019). Procrastination and personal finances: Exploring the roles of planning and financial self-efficacy. Frontiers in Psychology, 10, 110. https://doi.org/10.3389/fpsyg.2019.00775

Goldin, C., Katz, L. F., Kuziemko, I. (2006), The homecoming of American college women: The reversal of the college gender gap. The Journal of Economic Perspectives, 20(4), 133-157.

Haghbin, M. (2015). Conceptualization and operationalization of delay: Development and validation of the multifaceted measure of academic procrastination and the delay questionnaire. (Unpublished Ph.D. thesis). Carleton University, Ottowa, Canada.

Hashemi, M., Abbasi, M. (2013). The role of the teacher in alleviating anxiety in language classes. International Journal of Applied and Basic Sciences, 4(3), 640-646.

Horwitz, E. K., Horwitz, M.B., Cope, J. (1986). Foreign language classroom anxiety. The Modern Language Journal, 70(2), 125-132.

Klingsieck, K. B. (2013). Procrastination: When good things don't come to those who wait. European Psychologist, 18(1), 24-34. doi: 10.1027/1016-9040/a000138

Kornienko, A. A., Shamrova, D. P., Kvesko, S. B., Kornienko, A. A., Nikitina, Y. A., Chaplinskaya, Y. I. (2016). Adaptation Problems Experienced by International Students in Aspect of Quality Management. The European Proceedings of Social \& Behavioral Sciences, 48, 358-361 doi: 10.15405/epsbs.2017.01.48

Král'ová, Z., Sorádová D. (2015). Foreign Language Learning Anxiety. In: Teaching Foreign Languages in Inclusive Education: (A teacher-trainee's handbook), Nitra: Constantine the Philosopher University. doi: 10.17846/SEN.2015.91-100

Lee, S. (2008). Relationship between selected predictors and adjustment/acculturation stress among East Asian international students. (Doctoral dissertation). University of Kentucky, Lexington.

Lindblom-Ylänne, S., Saariaho, E., Inkinen, M., Haarala-Muhonen. A., Hailikari., T (2015). Academic procrastinators, strategic delayers and something betwixt and between: An interview study. Frontline Learning Research, 3(2), 47-62.

Markiewicz, K. (2018). Prokrastynacja i prokrastynatorzy. Definicja, etiologia, epidemiologia i terapia. Annales Universitatis Mariae Curie-Skłodowska, 31(3), 195-213.

Markiewicz, K., Dziewulska, P. (2018). Procrastination Predictors and moderating effect of personality traits. Polskie Forum Psychologiczne, 23(3), 593-609 doi: 10.14656/ PFP20180308

Pychyl, T.A., Sirois, F. M. (2016). Procrastination, emotion regulation, and well-being. In: Procrastination, Health, and Well-Being, (pp. 163-188). Academic Press,

Rorer, L. G. (1983). "Deep" RET: A reformulation of some psychodynamic explanations of procrastination. Cognitive Therapy and Research, 7, 1-10.

Russell, J., Rosenthal, D., Thomson, G. (2010). The international student experience: Three styles of adaptation. Higher Education, 60, 235-249

Sandhu, D. S., Asrabadi, B. R. (1994). Development of an acculturative stress scale for international students: Preliminary findings. Psychological Reports, 75(1,2), 435-448. doi: 10.2466/pr0.1994.75.1.435 
Schouwenburg, H. C., Lay, C. H., Pychyl, T. A., Ferrari, J. R. (Eds.). (2004). Counseling the Procrastinator in Academic Settings. Washington, DC: American Psychological Association. doi: 10.1037/10808-000

Sirois, F.M., Pychyl, T.A. (2013). Procrastination and the Priority of Short-Term Mood Regulation: Consequences for Future Self. Social and Personality Psychology Compass, 7(2), 115-127.

Steel, P. (2007). The nature of procrastination: a meta-analytic and theoretical review of quintessential selfregulatory failure. Psychological Bulletin, 133, 65-94. doi: 10.1037/00332909.133.1.65

Steel, P., Ferrari, J. (2013). Sex, education and procrastination: An epidemiological study of procrastinators' characteristics from a global sample. European Journal of Personality, 27(1), 51-58. doi: 10.1002/per.1851.

Tibbett, T. P., Ferrari, J. R. (2015). The portrait of the procrastinator: Risk factors and results of an indecisive personality. Personality and Individual Differences, 82 (2015), 175-184

Van Eerde, W., Klingsieck, K. B. (2018). Overcoming procrastination? A meta-analysis of intervention studies. Educational Research Review, 25, 73-85.

Zhanibek, A. (2001). The relationship between language anxiety and students' participation in foreign language classes. (Master thesis). Bilkent University, Ankara.

\section{References (translated and transliterated)}

Hrabchak, O. (2016). Osoblyvosti akademichnoji prokrastynaciji studentiv-pershokursnykiv [Academic procrastination features in first-year students]. Pedaghohika i Psykholohiya Profesiynoyi Osvity, 4, 210-218

Koltunovych, T.A., Polishhuk, O.M (2017). Prokrastynacija - konflikt mizh "vazhlyvym" i "pryjemnym" [Procrustination - the conflict between "important" and "pleasant"]. Young Scientist, 5 (45), 211-218.

Riadnova, V.V., Bezeha, N.M., Bezkorovaina, I.M., Voskresens'ka, L.K., Pera-Vasylchenko, A.V. (2018). Psykhologhichni osoblyvosti procesu adaptaciyi i orghanizaciyi navchannia studentiv-inozemtsiv [Psychological features of the process of adaptation and organization of international students' training]. Issues of Medical (Pharmaceutical) Education of International Citizens: Problems and Prospects. Book of abstracts. (74-76).

Balkis, M., Duru, E. (2019). Procrastination and Rational/Irrational Beliefs: A Moderated Mediation Model. Journal of Rational-Emotive \& Cognitive-Behavior Therapy. doi:10.1007/s10942-019-00314-6

Berry, J. W. (2005). Acculturation: Living successfully in two cultures. International Journal of Intercultural Relations, 29(6), 697-712. http://dx.doi.org/10.1016/j.ijintrel.2005.07.013

Chowdhury, S.F., Pychyl, T.A. (2018). A critique of the construct validity of active procrastination. Personality and Individual Differences, 120, 7-12. DOI: https://doi.org/ 10.1016/j.paid.2017.08.016.

DuBow, F. McCabe, E., Kaplan, G. (1979). Reactions to Crime: A Critical Review of the Literature, Unpublished report. Center for Urban Affairs, Northwestern University, Evanston, IL.

Ferrari J.R., Crum K.P., Pardo M.A. (2018), Decisional procrastination: Assessing characterological and contextual variables around indecision. Current Psychology, 37(2), doi: 10.1007/s12144-017-9681-x.

Ferrari, J. R., Johnson, J. L., McCown, W. G. (1995). The Plenum series in social/clinical psychology. Procrastination and task avoidance: Theory, research, and treatment. N.Y.: Plenum Press. doi: 10.1007/978-1-4899-0227-6

Ferrari, J. R., O'Callaghan, J., Newbegin, I. (2005). Prevalence of Procrastination in the United States, United Kingdom, and Australia: arousal and avoidance delays among adults. North American Journal of Psychology, 7(1), 1-6. 
Gamst-Klaussen, T., Steel, P., Svartdal, F. (2019). Procrastination and personal finances: Exploring the roles of planning and financial self-efficacy. Frontiers in Psychology, 10, 110. https://doi.org/10.3389/fpsyg.2019.00775

Goldin, C., Katz, L. F., Kuziemko, I. (2006), The homecoming of American college women: The reversal of the college gender gap. The Journal of Economic Perspectives, 20(4), 133-157.

Haghbin, M. (2015). Conceptualization and operationalization of delay: Development and validation of the multifaceted measure of academic procrastination and the delay questionnaire. (Unpublished Ph.D. thesis). Carleton University, Ottowa, Canada.

Hashemi, M., Abbasi, M. (2013). The role of the teacher in alleviating anxiety in language classes. International Journal of Applied and Basic Sciences, 4(3), 640-646.

Horwitz, E. K., Horwitz, M.B., Cope, J. (1986). Foreign language classroom anxiety. The Modern Language Journal, 70(2), 125-132.

Klingsieck, K. B. (2013). Procrastination: When good things don't come to those who wait. European Psychologist, 18(1), 24-34. doi: 10.1027/1016-9040/a000138

Kornienko, A. A., Shamrova, D. P., Kvesko, S. B., Kornienko, A. A., Nikitina, Y. A., Chaplinskaya, Y. I. (2016). Adaptation Problems Experienced by International Students in Aspect of Quality Management. The European Proceedings of Social \& Behavioral Sciences, 48, 358-361 doi: 10.15405/epsbs.2017.01.48

Král'ová, Z., Sorádová D. (2015). Foreign Language Learning Anxiety. In: Teaching Foreign Languages in Inclusive Education: (A teacher-trainee's handbook), Nitra: Constantine the Philosopher University. doi: 10.17846/SEN.2015.91-100

Lee, S. (2008). Relationship between selected predictors and adjustment/acculturation stress among East Asian international students. (Doctoral dissertation). University of Kentucky, Lexington.

Lindblom-Ylänne, S., Saariaho, E., Inkinen, M., Haarala-Muhonen. A., Hailikari., T (2015). Academic procrastinators, strategic delayers and something betwixt and between: An interview study. Frontline Learning Research, 3(2), 47-62.

Markiewicz, K. (2018). Prokrastynacja i prokrastynatorzy. Definicja, etiologia, epidemiologia i terapia. Annales Universitatis Mariae Curie-Skłodowska, 31(3), 195-213.

Markiewicz, K., Dziewulska, P. (2018). Procrastination Predictors and moderating effect of personality traits. Polskie Forum Psychologiczne, 23(3), 593-609 doi: 10.14656/ PFP20180308

Pychyl, T.A., Sirois, F. M. (2016). Procrastination, emotion regulation, and well-being. In: Procrastination, Health, and Well-Being, (pp. 163-188). Academic Press,

Rorer, L. G. (1983). "Deep" RET: A reformulation of some psychodynamic explanations of procrastination. Cognitive Therapy and Research, 7, 1-10.

Russell, J., Rosenthal, D., Thomson, G. (2010). The international student experience: Three styles of adaptation. Higher Education, 60, 235-249

Sandhu, D. S., Asrabadi, B. R. (1994). Development of an acculturative stress scale for international students: Preliminary findings. Psychological Reports, 75(1,2), 435-448. doi: 10.2466/pr0.1994.75.1.435

Schouwenburg, H. C., Lay, C. H., Pychyl, T. A., Ferrari, J. R. (Eds.). (2004). Counseling the Procrastinator in Academic Settings. Washington, DC: American Psychological Association. doi: 10.1037/10808-000

Sirois, F.M., Pychyl, T.A. (2013). Procrastination and the Priority of Short-Term Mood Regulation: Consequences for Future Self. Social and Personality Psychology Compass, $7(2), 115-127$.

Steel, P. (2007). The nature of procrastination: a meta-analytic and theoretical review of quintessential selfregulatory failure. Psychological Bulletin, 133, 65-94. doi: 10.1037/00332909.133.1.65 
Steel, P., Ferrari, J. (2013). Sex, education and procrastination: An epidemiological study of procrastinators' characteristics from a global sample. European Journal of Personality, 27(1), 51-58. doi: 10.1002/per.1851.

Tibbett, T. P., Ferrari, J. R. (2015). The portrait of the procrastinator: Risk factors and results of an indecisive personality. Personality and Individual Differences, 82 (2015), 175-184

Van Eerde, W., Klingsieck, K. B. (2018). Overcoming procrastination? A meta-analysis of intervention studies. Educational Research Review, 25, 73-85.

Zhanibek, A. (2001). The relationship between language anxiety and students' participation in foreign language classes. (Master thesis). Bilkent University, Ankara. 